Coimbra, C. M.

"Tensão ou oposição entre ciência e política na pós-graduação? um falso problema?"

\title{
TENSÃO OU OPOSIÇÃO ENTRE CIÊNCIA E POLÍTICA NA PÓS-GRADUAÇÃO? UM FALSO PROBLEMA?
}

\author{
Cecília Maria Coimbra \\ Universidade Federal Fluminense
}

RESUMO: Resistindo, denunciando, cansando, algumas vezes indignando-nos, a maioria do tempo estamos vivendo os extertores da universidade pública brasileira, em especial na área conhecida como Ciências Humanas e Sociais. Dentro do ideário neoliberal de Estado mínimo os recursos e financiamentos que têm sido alocados na educação superior pública e laica, em nosso país são, a cada ano, mais irrisórios. Interessa que, numa mesma universidade pública, os vários centros, institutos e departamentos se degladiem ferozmente entre si pelas verbas repassadas em migalhas e vindas como esmolas. As equipes, os professores e alunos competem uns com os outros pelos, cada vez mais, escassos financiamentos. São estas observaçōes que trago neste texto como notas introdutórias sobre a questão da universidade brasileira hoje, em especial, no que se refere ao sucateamento que vem sofrendo a chamada área de "humanidades", nos cursos de pós-graduação.

PALAVRAS-CHAVE: universidade pública, política, ciências sociais e humanas.

TENSION OR OPPOSITION BETWEEN SCIENCE AND POLITICS IN THE POSTGRADUATE? A FALSE PROBLEM?

ABSTRACT: Resisting, denouncing, tiring, sometimes becoming indignant, most of the time we are living the final moments of Brazilian public Universities, specially in the area known as Social and Human Sciences. In the neoliberal ideal of minimum State, the resources and financings that have been allocated in public collegeeducation in our country are, each year, more insignificant. It interests that, in a same public university, the several centers, institutes and departments ferociously struggle among themselves 
for the amount of money repassed in crumbs and coming as almses. The teams, the professors, the students compete against each other for the rare financings. These are the comments I bring in this text as introductory notes on the issue of Brazilian Universities today, specially concerned with devastation that, the so called "humanity" area has been suffering in Post-Graduation courses.

KEYWORDS: public university, politics, social and humans sciences.

Nas universidades, o que prevalece é o modelo de administração eficiente, capaz de gerar seus próprios recursos estabelecendo nexos cada vez mais profundos com o mercado e a corrida tecnológica. A eficácia do desempenho é medida em termos de sucessos estatísticos, de capitais, produtividade e visibilidade, todos conversiveis em valores de marketing para atrair novas parcerias, dotaçôes $e$ investimentos. (Nicolau Sevcenko)

Aos trancos e barrancos, resistindo - nem sempre utilizando as estratégias mais produtivas - denunciando, cansando - algumas vezes - indignando-nos - a maioria do tempo - estamos vivendo os extertores da universidade pública brasileira, em especial na área conhecida como Ciências Humanas e Sociais.

Estas observações que aqui trago são apenas pequenas notas introdutórias sobre a questão da universidade brasileira hoje, em especial, no que se refere ao sucateamento que vem sofrendo a chamada área de "humanidades", nos cursos de pós-graduação.

Dentro do ideário neoliberal de Estado mínimo os recursos e financiamentos que têm sido alocados na educação superior pública e laica, em nosso país são, a cada ano, mais irrisórios.

Interessa que, numa mesma universidade pública, os vários centros, institutos e departamentos se degladiem ferozmente entre si pelas verbas repassadas em migalhas e vindas como esmolas. As equipes, os professores e alunos competem uns com os outros pelos, cada vez mais, escassos financiamentos.

1 Termo utilizado pelo prof. Osvaldo Coggiola que aponta sua utilização como uma inclinação para destituir as ciências humanas de seu caráter científico. 
Coimbra, C. M.

"Tensão ou oposição entre ciência e política na pós-graduação? um falso problema?"

O professor ideal agora é um híbrido de cientista e corretor de valores. Grande parte de seu tempo deve ser dedicado a preencher relatórios, alimentar estatísticas, levantar verbas e promover visibilidade para si e seu departamento. O campus vai se configurando num gigantesco pregão (...). (SEVCENKO, 2000:7)

A universidade pública e laica, funcionando aos moldes de uma empresa capitalista - onde fazer pesquisa tem sido, antes de mais nada, o aumento abusivo de obrigaçōes burocráticas ${ }^{2}$ (informes, questionários, ênfase quantitativa em trabalhos que não serão lidos) - vem priorizando, não por acaso, através de seu órgãos financiadores de pesquisa, as chamadas ciências exatas e biológicas.

Ou seja, o sucateamento, o aviltamento da educação superior pública e laica em nosso país são agravados quando nos referimos às ciências humanas e sociais. Estas, em especial, a nível de pós-graduação, vêm sendo subalternizadas, desqualificadas e inferiorizadas em relação a outras áreas de conhecimento. ${ }^{3}$ O conhecimento tecnocrático, fundamento do próprio sistema capitalista, impõe-se como o melhor, o que deve merecer atenção e, portanto, ser priorizado.

Dentro do ideário racionalista - onde a reificação da ciência, enquanto instrumento objetivo e percebido como capaz de fornecer conclusões exatas, formular prognósticos confiáveis, em suma, "ge-

2 Um exemplo do arbítrio e da intolerância burocrática foi o que aconteceu comigo na Universidade Federal Fluminense, onde trabalho. Por erro, ao solicitar à PróReitoria de Pesquisa bolsas de iniciação científica do CNPq para dois alunos que comigo desenvolviam um projeto de pesquisa, em lugar do meu Currículo Lattes (única formatação de currículo hoje aceita) foi enviado um outro curriculum vitae das minhas atividades profissionais - uma outra formatação. As bolsas foram negadas sob o argumento de que um documento exigido no edital não foi apresentado e nem poderia mais ser aceito pois o prazo havia expirado. Durante um ano tive dois alunos pesquisando comigo sem bolsas do $\mathrm{CNPq}$, o que não só é um direito desses alunos, como pesou negativamente na minha avaliação de produtividade: eu não possuía alunos bolsistas oficiais.

3 Sobre este tema em especial consultar os vários artigos constantes na Revista da Adunicamp "Universidade e Humanidades" (2002), fruto de um seminário realizado, em abril de 2002, por essa entidade docente. Muitos desses artigos serão citados no decorrer destas notas introdutórias. 
rar tecnologias" - entende-se perfeitamente essa opção que vem, nos últimos quinze anos, sendo feita para as áreas tecnológicas e, não por acaso, chamadas de ciências exatas.

O "tecnicismos cientificista", estimulado pelo pensamento cartesiano dominante na academia e pela crença na razão universal, em muito tem servido ao sistema capitalista. Silva (2002:6) a isto se refere ao apontar que:

A humanidade jamais conheceu um sistema econômico capaz de gerar - de forma permanente e estrutural - tanta miséria e desigualdade social. Isso talvez explique a ausência de uma discussão minimamente razoável sobre o conhecimento tecnocrático, fundamento do próprio sistema capitalista. Este conhecimento se impóe pela força da ideologia dominante, sob o charmoso tacão da grande midia, mas também a golpes de critérios de rendimento e produtividade de governos e agências governamentais de fomento ao ensino e à pesquisa - critérios que a maioria da comunidade acadêmica acata, raramente com entusiasmo, por vezes constrangida, quase sempre em silêncio.

Talvez seja otimista a avaliação feita por Silva, ao assinalar o pouco entusiasmo, o constrangimento e, mesmo, o silêncio da comunidade acadêmica aos ditames dos financiamentos que vêm sendo repassados, em especial às áreas humanas e sociais. O que temos presenciado, de forma clara e explícita, é a adesão a tais ditames; é o reconhecimento e o acatamento de que determinadas pesquisas, em determinadas áreas, são menos nobres, e têm, portando, menor valor acadêmico. Aceita-se o "pesquisador de segunda classe" (NOBRE, 2002), aquele que vale menos intelectualmente e academicamente e, portanto, menos financeiramente.

Deleuze (1992:221) ao nos falar das sociedades contemporâneas que denominou de sociedades de controle, a isso se refere ao afirmar que:

(...) a empresa introduz o tempo todo uma rivalidade inexplicável como sã emulação, excelente motivação que contrapõe os individuos entre si e atravessa cada um, dividindo-o em si mesmo. O prin- 
Coimbra, C. M.

"Tensão ou oposição entre ciência e política na pós-graduação? um falso problema?"

cípio modulador do "salário por mérito" tenta a própria Educação Nacional: com efeito, assim como a empresa substitui a fábrica, a "formação permanente" tende a substituir a escola, e o controle contínuo substitui o exame. Este é o meio mais garantido de entregar a escola à empresa.

Um outro fator tem agravado, em especial, a situação das áreas humanas nas universidades brasileiras, sobretudo, a partir de 1994: o número crescente de aposentadorias, em função do pânico gerado no funcionalismo público, em geral, e nos docentes, em particular, pelas ameaças de reforma do Sistema Previdenciário. Dentro do vendaval neoliberal, as universidades, públicas em especial, perdem seus professores e desmontam-se grupos inteiros de pesquisa e extensão. Alguns levantamentos realizados atestam para o assustador número de professores que pedem afastamento dos estabelecimentos públicos e migram para os particulares, onde os salários são três vezes maiores. A saída desses docentes, em especial nas áreas humanas, não tem tido substituição, crescendo com isso o número de vagas de professores nessas áreas.

Não por acaso, florescem as universidades privadas. De um lado, o sucateamento das universidades públicas e, de outro, "que é um outro lado da mesma medalha, a enorme expansão das universidades privadas, que se transformaram hoje, ao lado dos hospitais e

4 Deleuze refere-se aqui à educação francesa que, em início da década de 90, já prenunciava a diferenciação de salários para os professores de uma mesma escola. Nas universidades federais brasileiras, isso foi colocado em funcionamento, desde o final dos anos 90, quando foi instituída a Gratificação de Estímulo à Docência (GED). Esta prevê que, de acordo com a produtividade anual do professor, este terá um acréscimo ou não ao seu salário.

$5 \mathrm{Na}$ USP, nos últimos sete anos, 782 professores se demitiram. A Unicamp "acusou a baixa de 170 nos últimos dois anos”. Na UFRJ, em 1996, 281 docentes deixaram a instituição. Na UFF, nos anos de 1995 a 1999, 415 professores se aposentaram. $\mathrm{Na} U \mathrm{UNB}$, de janeiro de 94 a novembro de 97, 253 professores saíram do quadro. In: "A Diáspora dos Cérebros" - Revista Veja - 10/12/97 e "Professores abandonam universidades públicas" in Jornal do Brasil - 13/02/98, p 9. Em agosto de 2003, dados do Ministério do Planejamento apontavam que a média das aposentadorias de servidores públicos federais alcançou 1.597 até julho. Ou seja, apenas no $1^{\circ}$ semestre de 2003, as aposentadorias "superaram o total dos que deixaram a atividade 
das igrejas nos três melhores negócios do Brasil" (OLIVEIRA, 2002:36).

Tal quadro - sucintamente apresentado - aponta para uma competente produção: existiria uma tensão e, mesmo, oposição entre ciência (representada pelas áreas tecnológicas) e política (representada pelas "humanidades").

Diante da "objetividade", "racionalidade", "cientificidade" e "previsibilidade” presentes nas áreas das ciências exatas e biológicas teríamos em oposição a subjetividade, a pouca racionalidade e cientificidade e nenhuma previsibilidade por parte das ciências humanas.

Entretanto, cabe perguntar: quem determina e como são determinados os temas que deverão ser pesquisados pela academia? $\mathrm{O}$ que é legítimo de ser pesquisado? Como se produz essa legitimidade? (NOBRE, op. cit).

Ou seja, como nos aponta Silva (op. cit: 6):

Quem define as possiveis aplicaçôes do conhecimento à realidade, à sociedade? Quem define as necessidades dos lugares e momentos em que o conhecimento é produzido? Quem define a tal demanda social que o conhecimento e a universidade deveriam atender? (...) tais definiçôes resultam fundamentalmente da ação dos donos do poder instituído, dos donos do mundo político, do mundo econômico, do

em 2002. (...) As universidades e escolas técnicas são um dos maiores focos (...) Levantamento realizado pela Associação Nacional dos Dirigentes das Instituiçōes Federais de Ensino Superior (ANDIFES) informa que, até início de junho de 2003, 2.000 professores e técnicos administrativos se aposentaram”. In "Aposentadorias deste ano já ultrapassam as de 2002" - Folha de São Paulo - 28/08/2003, pa - 6. Em entrevista, o sociólogo Octávio Ianni, ao se referir ao momento em que essas aposentadorias estão se dando, quando da votação da Reforma da Previdência pelo governo Lula, afirma que "um governo que vem a partir de movimentos sociais está se dedicando muito apressadamente a satanizar a atividade intelectual na universidade pública. Portanto, está contribuindo para favorecer a privatização e o economicismo no primeiro, segundo e terceiro graus, que é um item do ideário de Washington, ou mais concretamente uma exigência do Banco Mundial". In: "Governo 'sataniza' funcionalismo para aprovar reformas, diz Ianni”" in Jornal da Unicamp, julho de 2003, no 220, p7. 
Coimbra, C. M.

"Tensão ou oposição entre ciência e política na pós-graduação? um falso problema?"

mundo da informação e outros winners, decision-makers e shitmakers em geral; os últimos homens que dirigem e são dirigidos por essa terrivel máquina social que resulta da fusão do Estado e do grande capital: o capitalismo moderno, agora também global.

Em minha vida acadêmica, tenho tido algumas experiências que apontam claramente nesse sentido.

Se, de um modo geral, dentro dos ventos neoliberais, as agências de governo em nosso pais - mediante processos bastante perversos aumentam sobremaneira as exigências quanto à capacitação de docentes de 'nivel superior' e, paradoxalmente, diminuem as condiçôes para tal, tornando-as cada vez mais restritivas e desistimulatórias, o que dizer de pesquisas que fogem ao instituido no âmbito acadêmico? O que dizer de pesquisas que propóem pensar o político, quando a área do profissional é a Psicologia? (COIMBRA, 2000: 254)

Em junho de 1997, quando de minha solicitação à CAPES de uma bolsa para pós-doutorado, no sentido de pesquisar a articulação que vem sendo produzida entre pobreza e periculosidade em nosso país, o parecer negando o pedido dizia o seguinte, dentre outras coisas:

As questôes levantadas (...) quase todas pertinentes à questão dos direitos humanos (...) em muitos momentos assumem um aspecto exclusivamente de denúncia, de panfletagem. Por mais que se possa concordar com o teor das denúncias e reconhecer e admirar o valor da militância da candidata (...) um projeto não pode ser formulado sem uma certa especificação de objetivos $e$ metodologia.(grifos meus)

Dentro da metodologia então apresentada, à época, para aquele projeto de pós-doutorado, seguíamos, dentro do referencial da análise institucional francesa, a chamada pesquisa - intervenção, onde pesquisador e pesquisado, sujeito e objeto do conhecimento 
se constituem no próprio processo da pesquisa. Não aceitamos - e isto era enfatizado no projeto - um a priori e um a posteriori: um objeto como algo a ser apreendido, como um a priori a ser conhecido e analisado a posteriori, como uma verdade a ser encontrada.

Foi em cima de tais questôes, que um outro parecer, o da FAPESP, respondendo a uma outra solicitação minha de bolsa de pós-doutorado, baseou-se para também negar o pedido. De forma mais sofisticada, "científica e objetiva" que o parecer da CAPES, o da FAPESP, de agosto de 1997, argumentava que a metodologia era "obscura, confundindo método com técnicas".

Estes exemplos, como dezenas de outros que ocorrem cotidianamente, utilizando os argumentos da incompetência e da pesquisa pouco qualificada podem ser considerados como situaçóes analisadoras ${ }^{6}$ que põem a nu a pseudo-objetividade do "tecnicismo cientificista" e que apontam a quem e a que, em realidade, essas pesquisas e esses pesquisadores de "primeira classe", que têm uma reconhecida "cidadania acadêmica", têm servido.

Não por acaso, em especial nas áreas tecnológicas, a política de privatização das universidades brasileiras, "resultante dos acordos entre o Ministério da Educação e o Banco Mundial, ganha proporções cada vez maiores (...)” (PAGANI, 2002:41).

Pressionadas pela insuficiência de recursos, as universidades federais, em especial suas áreas tecnológicas, incorporam esses paradigmas de produtivismo como normas indiscutíveis.

As universidades brasileiras abrem assim seus campi para a iniciativa privada por meio de convênios formalizados com as empresas (...). Não obstante isso, vão, elas próprias assumindo o caráter de empresa privada, com a criação de fundações, por exemplo (PAGANI, op. cit.).

6 Por analisador entendemos, dentro das contribuições trazidas pela analise institucional francesa, acontecimentos que, por si só, colocam em análise as instituições, as relações percebidas como naturais e até mesmo necessárias. Tais acontecimentos falam por si, produzem sua própria análise. 
Coimbra, C. M.

"Tensão ou oposição entre ciência e política na pós-graduação? um falso problema?"

Em especial, nas áreas das ciências tecnológicas, encontramos, praticamente em todas as universidades públicas brasileiras, fundações de direito privado. De um modo geral, as humanas e sociais "como não têm fundação, como não vendem seus serviços no mercado, estão desprovidas de quase tudo" (OLIVEIRA, op. cit.).

Da mesma forma, naquelas mesmas áreas tecnológicas, cursos de extensão e especialização vêm sendo velozmente criados tendo como principais parcerias grandes empresas.

Seis anos após ter sido criada, a Escola de Extensão da Unicamp (Extecamp) dispunha, em 1995, de 451 propostas de cursos em seu catálogo. Quatro anos depois, em 1999, a oferta somava 1.095 cursos. Em 2002, o catálogo da escola oferece nada menos do que 1.738 cursos (REVISTA ADUNICAMP, 2002:43).

Oliveira (op.cit:40) chama a atenção para o fato de que nos programas dos mais diferentes partidos políticos, em especial nos que se colocam como de esquerda, não se encontra nenhuma menção ao aumento de verbas para as universidades públicas brasileiras.

Isso mostra o lugar que os partidos politicos, (...) reservam à universidade (...) Porque a Universidade pública suscita imediatamente - e ninguém pode fugir a isso - aumento dos gastos do Estado. E um gasto do Estado que está comprimido pela obrigação de apresentar um superávit primário de 3,57\% ao FMI. Desse modo, não tem ninguém que se meta a dizer escancaradamente "vou aumentar o gasto estatal com educação superior". E é isso que é preciso (...) Dai a grande vitória neo-liberal (...). Faz-se uma certa referência ao gasto que diretamente incide sobre as condiçōes de miséria, de pobreza do país, e não se fala de educação superior pública e laica, que é certamente um dos lugares onde gastos públicos podem ser mais eficientes para a democratização e para a aniquilação da pobreza. Eu não vejo isso nos programas políticos, infelizmente.

Diante do atual quadro político-econômico brasileiro o deputado federal Chico Alencar (2003) indaga se: 
Psicologia \& Sociedade; 16 (1): 86-97; Número Especial 2004

Os investimentos em educação, saúde, habitação e cultura continuarão restritos no Orçamento de 2004, substituindo-se as politicas sociais universais pelas açôes focadas, pontuais e de cunho assistencialista? (O GLOBO, 22/08/2003)

Diante desse quadro não há motivos, portanto, para estranhar a ausência de determinados temas mesmo nos cursos de graduação ligados às ciências humanas e sociais, nas suas pesquisas e extensões. Em especial na Psicologia, temas que se colocam como políticos têm sido classificados como não científicos, não acadêmicos; é como se fizessem parte de um outro território: o da militância. Daí, a sua quase total ausência nas pesquisas, extensões e nas pósgraduações.

Entretanto, há linhas de fuga, há singularidades atrevidamente sendo construídas; há, enfim, vida pulsando nos mais diferentes territórios, por mais estigmatizados, desqualificados ou mesmo negados. Há, apesar desses extertores que vivemos, rupturas sendo produzidas por mais microscópicas e invisíveis que sejam.

$\mathrm{Na}$ Psicologia estamos percorrendo alguns caminhos. Procuramos incluir a política como uma necessária dimensão de nossa prática. Pretendemos entender o homem, seus pensamentos, percepções, sentimentos e ações como produções histórico-sociais, assim como analisar os efeitos de nossas práticas enquanto profissionais-cidadãos produzidos e produtores que somos. Potencializar a vida e nos aliarmos a ela, em especial aos movimentos que se espalham pelo mundo, tem sido um dos nossos desafios.

Ou seja, a luta vai mudando de patamar, de estratégias, criando novos dispositivos.

Seatle, Quebec e Porto Alegre nos ensinam que os poderes têm cada vez mais dificuldade de se reunirem em qualquer lugar do planeta (...) A luta não terminou. Para além das ideologias, para além até mesmo das questôes de classe, agora o conflito concerne à própria vida, isto é à sua defesa ou à sua apropriação. (LAYMERT, 2002:28) 
Coimbra, C. M.

"Tensão ou oposição entre ciência e política na pós-graduação? um falso problema?"

\section{REFERENNCIAS}

CAPES. Resposta à solicitação de bolsa. Brasília, junho de 1997.

CHOMSKY, N. La liberalización financieira ha creado un senado virtual que gobierna el mundo. In: Rebelión: Notícia. Washington, fevereiro/1998.

COGGIOLA, O. Ciências Humanas: o que são, para que servem In Revista ADUNICAMP, ano 4, no 1, novembro de 2002, 07-18.

COIMBRA, C. M B. Operação Rio: o mito das classes perigosas. Rio de Janeiro: Oficina do Autor/Intertexto, 2001.

DELEUZE, G. Conversaçôes. Rio de Janeiro: Editora 34, 1992.

FAPESP. Resposta à solicitação de bolsa. São Paulo, agosto de 1997.

Folha de São Paulo. 28/08/2003.

JORNAL DO BRASIL. 13/02/1998.

JORNAL DA UNICAMP. julho de 2003, no 220.

LAYMERT, G. dos S. Perspectivas que a revolução micro-eletrônica e a internet abrem à luta pelo socialismo. In: Revista ADUNICAMP, ano 4, no. 1 , novembro de 2002, 19-28

NOBRE, M. As Ciências Humanas na encruzilhada do socialdesenvolvimentismo. In: Revista ADUNICAMP, ano 4, no 1 , dezembro de 2002, 29-34.

O GLOBO - 23/08/2003.

OLIVEIRA, F. de. As humanidades em um contexto de crise da universalidade In Revista ADUNICAMP, ano 4, no 1 , novembro de 2002, 35-40.

PAGANI, M. C. Oferta de cursos pagos cresce na Unicamp: universalização do conhecimento ou mercantilização do ensino? In: Revista ADUNICAMP, ano 4, $\mathrm{n}^{\circ} 1$, novembro de 2002, 41-42. 
REVISTA VEJA. 10/12/1997.

SEVCENKO, N. O Professor como corretor. In: Caderno Mais. Folha de São Paulo 04/06/2000.

SILVA, S. Um Ideal. In: Revista da ADUNICAMP, ano 4, no 1 , novembro de 2002, 05-06.

Cecilia Ma Coimbra é Psicóloga, Professora Adjunta da UFF, Pós-doutora em Ciência Política pela USP. Fundadora e atual Vicepresidente do Grupo Tortura Nunca Mais/RJ.

$O$ endereço eletrônico da autora é: gtnm@alternex.com.br

Cecília Maria Coimbra

Tensão ou oposição entre ciência e política na pós-graduação? Um falso problema? Recebido: 8/11/2003

Aceite final: 3/5/2004 